\title{
Assessment of Knowledge Regarding Osteoporosis Among Female Medical Students at King Faisal University, Saudi Arabia
}

\section{UTKARSH SHAHI*1, MUNTADHER AL-SALEH², MOJTABA BOKHEDER², MOHAMMED ALBATTAT², MUSTAFA AL-ALI²,} TUMADHIR ALKISHI², MOHAMMED ALSHAREET², ZAINAB AL SHUHAYB², ALSALEH ESSA³

INTRODUCTION: Osteoporosis is a worldwide public health problem that affects both male and females. It is a silent progressive disorder that affect skeletal system and leads to diminished bone density and fracture. Therefore, awareness, attitude and practices of people about osteoporosis contribute significantly in primary prevention and early detection of disease.

OBJECTIVE: The present study conducted to assess the knowledge of the female medical students at King Faisal University about osteoporosis in Saudi Arabia.

MATERIALS AND METHOD: A cross sectional study conducted at medical college of King Faisal University at Al-Ahsa region, Saudi Arabia. The study included all female medical students at King Faisal University, through an online self-administered questionnaire using the Osteoporosis Knowledge Assessment Tool (OKAT) questionnaire.

RESULTS: The total number of participants was 176 of female medical students, with $58.7 \%$ response rate. The age of participants ranged between 17 and 27 years, with a mean and standard deviation of $21.46 \pm 1.54$ years. The participant's knowledge score about osteoporosis was as follows: $65.1 \%$ had satisfactory knowledge, $32.2 \%$ had poor knowledge, and only $2.3 \%$ of the participants had good knowledge.

CONCLUSION: Most of the participants had a satisfactory knowledge score on osteoporosis. However, there was significant gap in knowledge regarding the risk factors such as high salt intake. Good knowledge score was significantly low in the present study compared to worldwide. Therefore, an educational effort is needed to improve knowledge and the quality and reliability of information about osteoporosis, targeted undergraduates and young females in Saudi Arabia.

KEYWORDS: Knowledge, Osteoporosis, Medical students, King Faisal University, Saudi Arabia, AlAhsa

\section{INTRODUCTION}

Osteoporosis is a worldwide public health problem that affects both male and females. ${ }^{1-3}$ It is one of the main health problems with high prevalence.4,5 Worldwide osteoporosis affects approximately 75 million people. ${ }^{4}$ In the United States (US), osteoporosis affects ten million Americans older than 50 years, with around $80 \%$ of them being women.

Osteoporosis is a silent progressive disorder that affects the skeletal system and leads to diminished bone density and fracture. ${ }^{6}$ Osteoporosis-related fractures (ORF) impose a major burden in terms of morbidity, mortality, and expenditure1. Globally, it is estimated that $70 \%$ of women by the age of 80 years will suffer osteoporosis at hip, spine or forearm, and $60 \%$ of osteoporotic women will experience one or more ORF, furthermore, the costs of osteoporosis-related fractures in the US were around $\$ 1.9$ billion. ${ }^{1}$

There are many modifiable and non-modifiable risk factors that can lead to osteoporosis such as vitamin $\mathrm{D}$ consumption, low calcium intake, and being a female especially postmenopausal.7,8 However, there is a lack in secondary prevention of fractures in individuals with Osteoporosisrelated fractures. ${ }^{9}$

Primary prevention and early detection are the key factors in decreasing the burden of the disease. ${ }^{4}$ Therefore, awareness, attitude, and practices of people about osteoporosis contribute significantly to primary prevention and early detection of disease. $^{10,11}$

Kingdom of Saudi Arabia (KSA) is not in the exception of osteoporosis. Osteoporosis in Saudi Arabia could be more severe than the rest of the world according to some studies. ${ }^{12,13}$ The prevalence of osteoporosis in Saudi Arabia is like that of countries with high prevalence such as America and Europe, for example, osteoporosis in postmenopausal Saudi women was found to be $24.3 \%$ in age $50-59$ years, $62 \%$ in age $60-69$ years and $73.8 \%$ in age $70-79$ years. ${ }^{14}$ Even though 
femoral osteoporosis-related fractures are costing Saudi Arabia billions annually. ${ }^{15}$ Public awareness among Saudi population about osteoporosis varies significantly. ${ }^{16,17}$ However, there were no studies have been performed to evaluate the Saudi women's knowledge, attitude and practice about osteoporosis in AlAhsa region. Therefore, the present study conducted to assess the knowledge of the female medical students at King Faisal University about osteoporosis.

\section{OBJECTIVES}

To assess the knowledge of female medical students at King Faisal University about osteoporosis and associated risk factors, signs, symptoms, diagnosis, management and prevention.

\section{METHODOLOGY}

Study Design: Cross-sectional study conducted at the medical college of King Faisal University at AlAhsa region Saudi Arabia. King Faisal University is the unique university at Al-Ahsa region, and includes different colleges besides the medical college. The study was conducted during the period from $01 / 12 / 2017$ to $30 / 2 / 2018$.

Study Population: The study included all female medical students at King Faisal University. All medical female students of all levels included in the study, and non-medical students excluded from the study. Male students and female medical interns excluded from the study.

Data Collection: An online self-administered questionnaire containing a set of questions regarding osteoporosis knowledge distributed. The questionnaire consisted of two aspects, the first one contained an identification data such as age, sex, marital status, nationality and educational level of the participant. The second part assessed the participant's Knowledge using the Osteoporosis Knowledge Assessment Tool (OKAT) questionnaire. ${ }^{18}$ The OKAT questionnaire compromised twenty true and false question about common knowledge of osteoporosis.

Data Analysis: Statistical Package for the Social Sciences (SPSS) (version 21) was used to analyze the collected data about osteoporosis knowledge. The Pearson's chi-square test used to compare the significant association between osteoporosis knowledge and risk factor. A p-value of $<0.05$ was established as significant. The osteoporosis knowledge of participant was scored as follows: each correct response scored one point, and each incorrect or not know response scored zero points. The total correct responses were given a score out of 20; the scores were categorized as follows: < 10: poor knowledge, 10-15: satisfactory knowledge, and >15: good knowledge.

Ethical Consideration: The study information provided to all participants online specifying that participation was voluntary and there was no benefit or consequence from either participating or not in the study. A consent of participation in the study considered once the volunteer fills the questionnaire. The participant students had the right to participate or not in the study. Furthermore, there was no identification of individual participants at all level of study and the collected information was confidential.

\section{RESULTS}

The total number of participants was 176 female medical students, with a $58.7 \%$ response rate. The age of participants ranged between 17 and 27 years, with a mean and standard deviation of $21.46 \pm 1.54$ years. 54\% of participants were between 17 and 21 years, and $46 \%$ were between 22-27years. All participants were of Saudi nationality and were non-smokers. $30.1 \%$ of the participants were from the second academic year, $23.3 \%$ were from the fifth year and $14.1 \%$ were from the third year. Most of the participants were single (73.3\%) and $26.7 \%$ were married. (Table -1).

\begin{tabular}{|c|l|c|c|}
\hline \multirow{2}{*}{ Age } & $17-21$ years & 95 & 54.0 \\
\cline { 2 - 4 } & $22-27$ & 81 & 46.0 \\
\hline \multirow{4}{*}{$\begin{array}{c}\text { Educationa } \\
\text { 1 level }\end{array}$} & First Year & 27 & 15.3 \\
\cline { 2 - 4 } & Second Year & 53 & 30.1 \\
\cline { 2 - 4 } & Third Year & 25 & 14.2 \\
\cline { 2 - 4 } & Fourth Year & 30 & 17.0 \\
\cline { 2 - 4 } & Fifth Year & 41 & 23.3 \\
\hline \multirow{4}{*}{$\begin{array}{c}\text { Marital } \\
\text { status }\end{array}$} & Married & 47 & 26.7 \\
\cline { 2 - 4 } & Single & 129 & 73.3 \\
\hline
\end{tabular}

Table 1. Demographic Characteristics of Respondents 
The participant's knowledge score was as follows: $65.1 \%$ had satisfactory knowledge, $32.2 \%$ had poor knowledge, and only $2.3 \%$ of the participant had good knowledge on signs, symptoms, risk factors, diagnosis, prevention and treatment of osteoporosis, based on the categorization defined in the methodology (Table-2).

\begin{tabular}{|c|c|}
\hline \multicolumn{2}{|c|}{ Knowledge score } \\
\hline Knowledge score & N (\%) \\
\hline Poor knowledge $(<10)$ & $57(32.4)$ \\
\hline $\begin{array}{c}\text { Satisfactory knowledge } \\
(10-15)\end{array}$ & $114(64.8)$ \\
\hline Good knowledge $(>15)$ & $5(2.8)$ \\
\hline
\end{tabular}

Table 2. Knowledge score of osteoporosis among the respondents

It was observed that $56.4 \%$ of participants with age between 17-21 years had satisfactory knowledge as compared to $75.3 \%$ of those with age between 22 27 years. $4.9 \%$ of participants with age between 22 27 had good knowledge as compared to zero percent of those with age 17-21 years. There was a statistical significant association between age and knowledge score $\llbracket\left(x \rrbracket^{\wedge} 2=14.6, \rho=0.001\right)$ (Table-3).

A total of $70.2 \%$ of married participants had satisfactory knowledge level as compared to $63.3 \%$ unmarried. Moreover, $\mathbf{2 7 . 7 \%}$ of married participants' students had poor knowledge compared to $34.4 \%$ of single ones. However, there was no statistical significant association between a marital status of students and knowledge level. $\llbracket\left(x \rrbracket^{\wedge} 2=0.73, \rho=0.69\right)$. (Table - 3$)$

The majority of the participants who studied at 5 th level (87.8\%) had satisfactory knowledge score as compared to those in $4^{\text {th }}$, 3rd, 2nd, ist level with $(66.7 \%, 56 \%, 56.6 \%$, and 53.8\%), respectively. Moreover, $75 \%$ of participants of 4 th level had good knowledge as compared to $25 \%$ of 5 th level, and none from other levels. There was a statistical significant association between educational level and knowledge score $\llbracket\left(x \rrbracket^{\wedge} 2=26.5, \rho=0.001\right)$ (Table3).

The responses regarding the risk factors, signs, symptoms, diagnosis, management and prevention of osteoporosis vary between participants. Most of the participants' students (98.9\%) considered the osteoporosis as a risk of fractures. Whilst, $35.8 \%$ knew symptoms of osteoporosis that happen before bone fracture. On the other hand, $16.5 \%$ of students knew correctly that high salt intake is a risk factor for osteoporosis. Moreover, more than half of participants had the knowledge about bone loss in the first ten years following the onset of menopause (Table -4).

\section{DISCUSSION}

Worldwide osteoporosis has a high prevalence and considered to be one of the most common musculoskeletal disorders. ${ }^{17}$ Therefore, the success of osteoporosis prevention and control based on the level of knowledge of people toward osteoporosis. ${ }^{17,18}$ The purpose of the present study was to assess knowledge regarding osteoporosis among female medical students at KFU. Female medical students were selected as they would not have special teaching about osteoporosis in the medical college.

The current study showed that the mean age of participants was $21.461 \pm 1.54$ years, which is similar to the age from other studies such as; Malaysian study among private university students which reported an age of $22.91 \pm 1.74$ years, ${ }^{4}$ and Sri Lanka study among university students which showed age of $20 \pm 21$ years. ${ }^{19}$

The current study reported $32.6 \%$ of participants' students had poor knowledge score about osteoporosis which is lower than what is reported by Amin et al (79.4\%). ${ }^{4}$ Another study done in Pakistan among young female showed $17.9 \%$ had poor knowledge and $82.1 \%$ had good knowledge about osteoporosis. ${ }^{20}$

The present study showed $98.9 \%$ of participants considered osteoporosis a risk of fractures. This finding came in opposite to another study, which reported $91.7 \%$ of respondents knew osteoporosis is a disease, but 'false' statement was stated by $80.3 \%$ regarding osteoporosis causes bone weak and brittle. ${ }^{4}$

Knowledge upon the risk of fractures, sign, and symptoms, and prevention measures about osteoporosis is considered as an important factor in lowering the morbidity as well as in preventing osteoporosis. However, knowledge about osteoporosis among the participants in the 


\begin{tabular}{|c|c|c|c|c|c|c|c|c|}
\hline \multirow{3}{*}{\multicolumn{2}{|c|}{ Demographic characteristics }} & \multicolumn{6}{|c|}{ Knowledge Score } & \multirow[b]{2}{*}{$\left(x^{2}, \rho\right)$} \\
\hline & & \multicolumn{2}{|c|}{ Poor knowledge } & \multicolumn{2}{|c|}{$\begin{array}{l}\text { Satisfactory } \\
\text { knowledge }\end{array}$} & \multicolumn{2}{|c|}{ Good knowledge } & \\
\hline & & Count & $\%$ & Count & $\%$ & Count & $\%$ & \multirow{3}{*}{$(14.6,0.001)$} \\
\hline \multirow[t]{2}{*}{ Age } & 17-21 years & 41 & 43.6 & 53 & 56.4 & 0 & o & \\
\hline & 22-27 years & 16 & 19.8 & 61 & $75 \cdot 3$ & 4 & 4.9 & \\
\hline \multirow[t]{2}{*}{ Marital status } & Married & 13 & $27 \cdot 7$ & 33 & 70.2 & 1 & 2.1 & \multirow[t]{2}{*}{$(0.74,0.69)$} \\
\hline & Single & 44 & 34.4 & 81 & 63.3 & 3 & 2.3 & \\
\hline \multirow{5}{*}{ Educational level } & First year & 12 & 46.2 & 14 & 53.8 & o & o & \multirow{5}{*}{$(26.6,0.001)$} \\
\hline & $\begin{array}{c}\text { Second } \\
\text { year }\end{array}$ & 23 & 43.4 & 30 & 56.6 & o & o & \\
\hline & Third year & 11 & 44.0 & 14 & 56.0 & o & o & \\
\hline & Fourth year & 7 & 23.3 & 20 & 66.7 & 3 & 10.0 & \\
\hline & Fifth year & 4 & 9.8 & 36 & 87.8 & 1 & 2.4 & \\
\hline
\end{tabular}

Table 3. Knowledge Score of Osteoporosis among The Respondents

\begin{tabular}{|c|c|c|c|}
\hline \multicolumn{2}{|l|}{ Questions } & \multirow{2}{*}{ Count } & \multirow{2}{*}{$\frac{1}{98.9 \%}$} \\
\hline Osteoporosis leads to an increased risk of bone fractures. & True & & \\
\hline Osteoporosis usually causes symptoms (e.g. pain) before fractures occur. & False & 63 & $35.8 \%$ \\
\hline $\begin{array}{l}\text { Having a higher peak bone mass at the end of childhood gives no protection against the } \\
\text { development of osteoporosis in la }\end{array}$ & True & 36 & $20.5 \%$ \\
\hline Osteoporosis is more common in men. & False & 159 & $90.3 \%$ \\
\hline Cigarette smoking can contribute to osteoporosis & True & 142 & $80.7 \%$ \\
\hline White women are at highest risk of fracture as compared to other races. & True & 56 & $31.8 \%$ \\
\hline A fall is just as important as low bone strength in causing fractures. & True & 107 & $60.8 \%$ \\
\hline By age 80 , the majority of women have osteoporosis. & True & 136 & $77.3 \%$ \\
\hline From age 50, most women can expect at least one fracture before they die. & True & 61 & $34.7 \%$ \\
\hline Any type of physical activity is beneficial for osteoporosis. & False & 68 & $38.6 \%$ \\
\hline It is easy to tell whether I am at risk of osteoporosis by my clinical risk factors. & True & 104 & $59.1 \%$ \\
\hline Family history of osteoporosis strongly predisposes a person to osteoporosis. & True & 138 & $78.4 \%$ \\
\hline An adequate calcium intake can be achieved from two glasses of milk a day. & True & 62 & $35.2 \%$ \\
\hline Sardines and broccoli are good sources of calcium for people who cannot take dairy products. & True & 72 & $40.9 \%$ \\
\hline Calcium supplements alone can prevent bone loss. & False & 121 & $68.8 \%$ \\
\hline Alcohol in moderation has little effect on osteoporosis. & True & 50 & \\
\hline A high salt intake is a risk factor for osteoporosis. & True & 29 & $16.5 \%$ \\
\hline There is a small amount of bone loss in the ten years following the onset of menopause. & False & 64 & $36.4 \%$ \\
\hline Hormone therapy prevents further bone loss at any age after menopause. & True & 103 & $58.5 \%$ \\
\hline There are no effective treatments for osteoporosis. & False & 98 & $55.7 \%$ \\
\hline
\end{tabular}

Table 4. Percentage of Correct Responses Of Various Questions Regarding Knowledge Of Osteoporosis Among The Respondents 
present study was poor compared to a study done among U.S. medical students. ${ }^{21}$

In the other hand, the current study showed higher satisfactory knowledge (65.1\%) compared to what is reported in a similar study among female medical school entrants in Sri Lanka $(51.6 \%) .{ }^{19}$

Another study done in Turkey among the medical students showed poor knowledge about risk factors and diseases resulting in osteoporosis. ${ }^{22}$ Several types of research reported poor knowledge about osteoporosis among women. ${ }^{23,24}$

Only $2.5 \%$ of the participants in the current study achieved a good knowledge score about osteoporosis, in contrast to $8 \%$ of participants had good knowledge in a study among female medical school entrants in Pakistan 5, and in Sri Lanka. ${ }^{19}$ Moreover, another study done in Pakistan reported knowledge score among university students as 13.01. ${ }^{25}$ Therefore, there are variations in knowledge score about osteoporosis worldwide. Cognitive skills (including knowledge) can be affected significantly by education. Several studies done in KSA, Iran, and Turkey reported a significant association between educational level and awareness about osteoporosis. ${ }^{17,26-28}$

One of the significant findings of the present study was that participants at fourth level had good knowledge score as compared to other levels, however in the opposite to this finding, one study reported bachelor student had more poor knowledge than foundation students. ${ }^{4}$ Moreover, another study showed no significant difference between osteoporosis knowledge among the students of both undergraduates and postgraduates. ${ }^{29}$

Hurst and Wham reported that age can affect knowledge level and osteoporosis Knowledge increased with increasing the age of the participants. "The current study showed that the younger the participant, the less knowledge about osteoporosis. This result contradicts a study done in the USA on postmenopausal women. ${ }^{30}$ However, this is consistent with another study done in Aseer, KSA (2012), which found that the level of knowledge was very poor especially among young women..$^{31}$ This may be explained by the community conservative in some regions of Saudi Arabia. On the other hand, a study done in Iran in general population didn't find any association between the level of awareness and age. ${ }^{26}$

The present study encountered some limitations: only one medical college was included. Moreover, some contributing factors were not explored in this study such as the source of information, socioeconomic factors and access to facilities. Another research that will include all medical colleges in Saudi Arabia is needed to be done to explore the level of knowledge among medical students all over Saudi Arabia. Furthermore, another research is needed to study the relationship between student knowledge about osteoporosis and other contributing factors.

This study pointed out the need for a health education campaign about osteoporosis targeted females at all levels of education and all ages. Furthermore, an educational program about the prevention and control of osteoporosis should be carried out all over the kingdom of Saudi Arabia targeting undergraduate students.

\section{CONCLUSION}

Most participants had a satisfactory knowledge score on osteoporosis in the present study. However, there was a significant gap in knowledge regarding the risk factors such as high salt intake. The good knowledge score was significantly low in the present study compared to worldwide. Therefore, the current study recommends better involvement of health authorities, and higher educational authorities in an educational effort to improve knowledge and the quality and reliability of information about osteoporosis targeted undergraduates and young females in Saudi Arabia.

\section{Acknowledgment}

We would like to Acknowledge all the medical students who participated in the study. Especial thanks to those who shared in data collection and to the administration in KFU for their facilitation the conduction of the study.

\section{REFERENCES}

1. Chapurlat R GH. Osteoporosis- ClinicalKey. In: Endocrinology: Adult and Pediatric 7 Aug 2017; Available From: https://www.clinicalkey.com/ - 
!/content/book/3-S2.0-B978032318907100069X? scroll $T o=\% 23$ hloooo 534

2. Danish SH, Ahmad F, Hassan F, et al. Osteoporosis and its associated factors revisited: ase control study. Pakistan Journal of Medicine and Dentistry 2014;3(2):13-20.

3. WHO. Assessment of osteoporosis at the primary health care level. Summary Report of a WHO Scientific Group. 2007. Geneva: World Health Organization.

4. Amin S, Mukti NA. Assessment of Knowledge Level on Osteoporosis among a Private University Students in Malaysia. Imperial Journal of Interdisciplinary Research. 2017;3(3):141-5.

5. Bilal M, Haseeb A, Merchant AZ, et al. Knowledge, beliefs and practices regarding osteoporosis among female medical school entrants in Pakistan. Asia Pacific family medicine. 2017;16(1):2-7.

6. Weppner DAR, Lo P. Osteoporosis- Clinical Key. In: Ferri's Clinical Advisor 20187 Aug 2017, Available from: https://www.clinicalkey.com/!/content/book/3-S2 .0-B9780323280495005754.

7. Edmonds E, Turner LW, Usdan SL. Osteoporosis knowledge, beliefs, and calcium intake of college students: Utilization of the health belief model. Open Journal of Preventive Medicine. 2012;2(1):27-34.

8. Ahmad MS, Mohamed IN, Mokhtar SA, Shuid AN. Review of the risk factor of osteoporosis in the Malaysian population. RUMes. 2014;3:77-82.

9. Leslie W, Giangregorio L, Yogendran M, et al. A population-based analysis of the post-fracture care gap 1996-2008: the situation is not improving. Osteoporosis International. 2012;23(5):1623-9.

10. Toh LS, Lai PSM, Wu DB-C, Wong KT, Low BY, Anderson $C$. The development and validation of the Osteoporosis Prevention and Awareness Tool (OPAAT) in Malaysia. PloS one. 2015;10(5):e0124553.

11. von Hurst PR, Wham CA. Attitudes and knowledge about osteoporosis risk prevention: a survey of New Zealand women. Public Health Nutrition. 2007;10(7):747-3.

12. Sadat-Ali M, Al-Habdan IM, Al-Turki HA, Azam MQ. An epidemiological analysis of the incidence of osteoporosis and osteoporosisrelated fractures among the Saudi Arabian population. Annals of Saudi medicine. 2012;32(6):637-641.

13. Hassan SSA, Hassan HS. Assessment of knowledge and practice toward osteoporosis in
Riyadh, KSA. International Journal of Advanced Research 20175(7):2179-83.

14. El-Desouki MI. Osteoporosis in postmenopausal Saudi women using dual x-ray bone densitometry. Saudi Medical Journal 2003; 24(9):953-6.

15. Alwahhabi BK. Osteoporosis in Saudi Arabia: Are we doing enough? Saudi Medical Journal. 2015;36(10):1149-50.

16. Barzanji AT, Alamri FA, Mohamed AG. Osteoporosis: a study of knowledge, attitude and practice among adults in Riyadh, Saudi Arabia. Journal of community health. 2013;38(6):1098-105. 17. Alamri FA, Saeedi MY, Mohamed A, Barzanii A, Aldayel M, Ibrahim AK. Knowledge, attitude, and practice of osteoporosis among Saudis: a community-based study. The Journal Of The Egyptian Public Health Association. 2015;90(4):171-7.

18. Winzenberg TM, Oldenburg B, Frendin S, Jones G. The design of a valid and reliable questionnaire to measure osteoporosis knowledge in women: the Osteoporosis Knowledge Assessment Tool (OKAT). BMC musculoskeletal disorders. 2003;4(1):17.

19. de Silva REE, Haniffa MR, Gunathillaka KDK, Atukorala I, Fernando EDPS, Perera WLSP. A descriptive study of knowledge, beliefs and practices regarding osteoporosis among female medical school entrants in Sri Lanka. Asia Pacific family medicine. 2014;13(1):15.

2o. Tahir M, Noman-ul-Haq AN, Razzaque G. Effect of Educational Intervention on Osteoporosis Knowledge among University Female Students in Quetta, Pakistan. Health. 2015;9:10.

21. Kasper MJ, Peterson MG, Allegrante JP, Galsworthy TD, Gutin B. Knowledge, beliefs, and behaviors among college women concerning the prevention of osteoporosis. Archives of family medicine. 1994;3(8):696-702.

22. Eyigör S, Karapolat H, Durmaz B. Medical students' knowledge of osteoporosis in Ege University Faculty of Medicine. Archives of Rheumatology 2008;23(3):77-81.

23. Pande K, Pande S, Tripathi S, Kanoi R, Thakur A, Patle S. Poor knowledge about osteoporosis in learned Indian women. Journal of The Association of Physicians of India 2005;53:433-6.

24. Ribeiro V, Blakeley J, Laryea M. Women's knowledge and practices regarding the prevention and treatment of osteoporosis. Health care for women international 2000;21(4):347-53. 
25. Haq N, Tahir M, Iqbal Q, Naseem Q. Exploration of Osteoporosis Knowledge and Perception among Young Women in Quetta. Pakistan. J Osteopor Phys Act 2015;3(3):1-6.

26. Firouz Amani, Ghorbani A, Ghezelbash S, Barak M, Frazaneh E. The level of people's awareness of osteoporosis in Ardabil City; A survey based study. International Journal of Medical Research and Health Sciences. 2015;4(1):158-63.

27. Mansoureh S, Elahe A, Hossein S. Awareness of osteoporosis among female employees in Kerman, Iran. Russian Open Medical Journal. 2015;4(1).

28. Ungan M, Tümer M. Turkish women's knowledge of osteoporosis. Family practice. 2001;18(2):199-203.
29. Khan YH, Sarriff A, Khan AH, Mallhi TH. Knowledge, attitude and practice (KAP) survey of osteoporosis among students of a tertiary institution in Malaysia. Tropical Journal of Pharmaceutical Research. 2014;13(1):155-162.

30. Akinpetide GO. Osteoporosis Knowledge, Beliefs, and Bone Promotion Behaviors of Postmenopausal African American (AA) Women. 2014. Disertation Available online from https://pqdtopen.proquest.com/doc/153639239o.ht $m l$ ? FMT $=A I$

31. Osman AA. Assessment of Osteoporosis KAP among women in Assir region, Saudi Arabia. Journal of Medicine and Medical Sciences. 2013;4(2):50-5.

Source of support: Nil, Conflict of interest: None declared

Cite this article as:

Shahi U, Al-Saleh M, Bokheder M, Albattat M, Al-Ali M, Alkishi T, Alshareet M, Al Shuhayb Z, AlSaleh E. Clinical and Radiographic Characteristics of the Primary Teeth Indicated For

Pulpectomy: A Cross-Sectional Analysis. Int Healthc Res J. 2018;2(10):253-259.

doi: 10.26440/ihrj.v2i10.189

\section{AUTHOR AFFILIATIONS:}

1. $\quad$ B.Sc, MBBS, PGDHA, MS, M.Ch., SICOT. King Faisal University, College of Medicine, Saudi Arabia

2. MBBS, King Faisal University, Saudi Arabia

3. MBBS, DEP, DrPH, Ministry of Health, Saudi Board Program of Preventive Medicine at AlAhsa, Saudi Arabia

\section{*Corresponding Author:}

Dr. Utkarsh Shahi

B.Sc, MBBS, PGDHA, MS, M.Ch., SICOT.

King Faisal University

College of Medicine

Saudi Arabia
For article enquiry/author contact details, e-mail at: editor.ihrj@gmail.com, editor@ihrjournal.com 